\section{When suspected 'runner's colitis' in a marathon runner turns out to be cancer-and in the end leads to a new personal best marathon time}

\author{
Peter Steiner
}

In the autumn of 2016, I completed my second marathon. I was an ambitious 35 -year-old athlete, participating yearround in activities that included running, road cycling, triathlon and alpine skiing. I was fit and well, and apart from pollen allergies I had not had any medical treatment. Approximately 3 hours after the marathon, I developed my first episode of bloody diarrhoea. As a doctor, I suspected this to be runner's colitis but was not overly concerned. I knew that a proportion of marathon runners report gastrointestinal complaints. ${ }^{1}$

\section{PERSISTING SYMPTOM LED TO A WORRISOME DIAGNOSIS}

In the following days, my diarrhoea disappeared, but the blood in my stool persisted.

Without any worrisome thoughts, I first underwent a proctoscopy which showed small haemorrhoids. These were treated, but because I still had blood in my stool I had a sigmoidoscopy a few weeks later. At this investigation, the gastroenterologist showed me the tumour in my rectum, and I knew what this meant. I had a biopsy, and the information from this (and the requisite additional imaging) meant that I was needed radiochemotherapy and surgery.

\section{PREOPERATIVE EXERCISE TRAINING}

Before the operation, I searched for additional support from sport and exercise medicine specialists as I knew this would help me through my therapy. I was advised to undertake a symptom-limited cardiopulmonary exercise tolerance test, and I did this in my second week of radiochemotherapy (under the supervision of a cardiologist). Based on that test, my physicians and I developed a training plan leading up to the operation. It included an intensive training week immediately after finishing radiochemotherapy. I was so happy that this plan allowed me to

Department of General Internal Medicine, Inselspital, Bern University Hospital, University of Bern, Bern, Switzerland

Correspondence to Dr Peter Steiner, Inselspital Universitatsspital Bern, Bern 3010, Switzerland; peter.steiner3012@gmail.com exercise in a training camp that had been planned prior to my diagnosis and to join my friends who are in good health.

\section{OPERATION}

Six months after my initial symptoms, I underwent surgery and the tumour was completely resected. Because the surgeon used robot-assisted surgery in my operation, I was able to avoid a second operation and this meant my recovery was faster as a result. I was also able to recover even quicker because the multidisciplinary tumour board recommended that I did not need chemotherapy at the same time.

\section{RECOVERY AND HIGHER-LEVEL COMEBACK}

I was able to slowly restart my running training 6 weeks after surgery and my cycling training 8 weeks after surgery. Twelve weeks after surgery, I had another exercise test which showed I was making a good recovery. Six months after surgery, I was able to run a half marathon in 1 hour 39 min! During this half marathon, all of my memories from diagnosis, radiochemotherapy, the operation, the stay in the hospital and the recovery phase afterwards came up. At the end of the race, I was physically tired and also emotionally exhausted, and I almost cried at the finish line.

Two years after I first experienced my symptoms, I was able to run the same marathon course. This time I could focus my thoughts more on the race, but the idea came to me to share my story with other patients. I intended to publish my story if I ran faster than I did prior to my diagnosis, and I achieved this by $9 \mathrm{~min}$ and I also recorded a new personal best of 3:34:18-I have the proof on Strava (see figure 1).

\section{ADVICE FOR OTHER PATIENTS}

Hopefully my experiences and other reports ${ }^{23}$ show that giving patients support with their training while they are undergoing treatment for cancer will encourage them to try to return to their pre-treatment fitness levels. In my case, this happened even after major abdominal surgery.

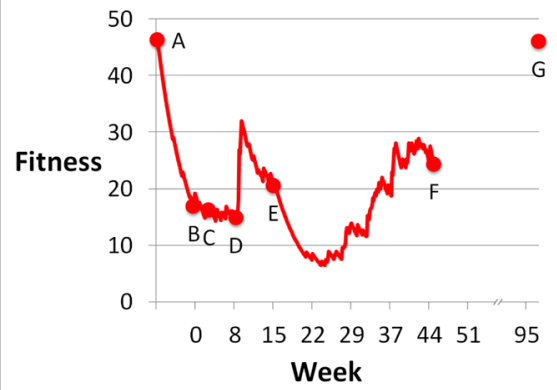

Figure 1 Fitness course according to strava between the marathon pre and post rectal cancer diagnosis. Time point of diagnosis is set at week zero. Marked time points with corresponding fitness: A) Marathon 7 weeks before diagnosis: 46.29. After the marathon I planned a 2 month recreation break.

B) Diagnosis of the rectal carcinoma: 17.78 .

C) Start of radiochemotherapy 2.5 weeks post diagnosis: 16.10. D) End of radiochemotherapy 8 weeks post diagnosis: 14.49 . Immediately at the end of the radiochemotherapy I went on a previously planned training camp with a fitness peak of 31.97. E) Operation 15.5 weeks post diagnosis: 20.57. Training was stopped for 6 week after the operation and slowly restarted. F) Half marathon 45 weeks post diagnosis: 24.52. G) Marathon 97 weeks post diagnosis regain of a former fitness level: 46.05 .

As there are increasing numbers of young and physically active individuals who are being diagnosed with colorectal cancer, I feel that this will become increasingly more relevant. I am still having minor stool irregularities and I do not know if I would be able to finish a challenge which is even more demanding (eg, Ironman triathlon) where nutrition and digestion are vital factors. I am happy that I am still able to perform physical exercise at a high level and maintain a normal lifestyle. I am sure that persisting with sport during both my therapy and my recovery definitely had an influence in both overcoming my cancer and the medical and psychological effects it had on my life.

\section{ADVICE FOR CLINICIANS}

Three bits of advice for clinicians working with exercising patients with colorectal cancer:

1. Patients with cancer (especially those who are used to exercising) can and should be supported during their therapy and recovery to help regain their former fitness level. Training at this time may also help to address the medical and psychological effects of the cancer too. 


\section{Patient voices}

2. In setting up a training plan for a patient with cancer, it is enormously helpful to know the condition of a patient and their treatment course, to specifically adapt the training to their needs.

3. Stool irregularities after colorectal surgery are normal, and improvements may take years. A comeback on an ambitious level is possible and a normal lifestyle can be achieved after major abdominal surgery.

Contributors PS wrote the manuscript.
Funding The authors have not declared a specific grant for this research from any funding agency in the public, commercial or not-for-profit sectors.

Competing interests None declared.

Patient consent for publication Obtained.

Provenance and peer review Not commissioned; internally peer reviewed.

(C) Author(s) (or their employer(s)) 2020. No commercial re-use. See rights and permissions. Published by BMJ.

\section{A) Check for updates}

To cite Steiner P. Br J Sports Med 2020;54:311-312. Accepted 18 July 2019

Published Online First 2 August 2019
Br J Sports Med 2020;54:311-312.

doi:10.1136/bjsports-2019-100675

\section{ORCID iD}

Peter Steiner http://orcid.org/0000-0002-3135-1239

\section{REFERENCES}

1 Heer M, Repond F, Hany A, et al. Acute ischaemic colitis in a female long distance runner. Gut 1987;28:896-9.

2 Meyer JE, Narang T, Schnoll-Sussman FH, et al. Increasing incidence of rectal cancer in patients aged younger than 40 years. Cancer 2010;116:4354-9.

3 Savage PD, Dittus K, Lakoski SG. Fitness during breast cancer treatment and recovery in an athlete: a case study. Med Sci Sports Exerc 2016;48:1893-7. 